Supplement of Biogeosciences Discuss., 12, 15809-15833, 2015

http://www.biogeosciences-discuss.net/12/15809/2015/

doi:10.5194/bgd-12-15809-2015-supplement

(C) Author(s) 2015. CC Attribution 3.0 License.

(c) (1)

Supplement of

\title{
Ocean acidification modulates expression of genes and physiological performance of a marine diatom
}

\author{
Y. Li et al. \\ Correspondence to: K. Gao (ksgao@xmu.edu.cn) and K. Wang (wkjian@xmu.edu.cn)
}

The copyright of individual parts of the supplement might differ from the CC-BY 3.0 licence. 
Table S1 Carbonate chemistry parameters of the growth medium for ambient (390 $\mu$ atm;

LC) and elevated $\mathrm{CO}_{2}(1000 \mu \mathrm{atm} ; \mathrm{HC})$ cultures. TA stands for total alkalinity. The values are means $\pm S D, n=3$. Different superscripted letters represent significant difference between the ambient and acidified conditions.

\begin{tabular}{ccccccc}
\hline $\mathrm{pCO}_{2}$ & $\mathrm{pH}_{\mathrm{NBS}}$ & $\begin{array}{c}\mathrm{DIC} \\
\left(\mu \mathrm{mol} \mathrm{kg}{ }^{-1}\right)\end{array}$ & $\begin{array}{c}\mathrm{HCO}_{3}{ }^{-} \\
\left(\mu \mathrm{mol} \mathrm{kg}{ }^{-1}\right)\end{array}$ & $\begin{array}{c}\mathrm{CO}_{3}{ }^{2-} \\
\left(\mu \mathrm{mol} \mathrm{kg}{ }^{-1}\right)\end{array}$ & $\begin{array}{c}\mathrm{CO}_{2} \\
(\mu \mathrm{mol} \\
\left.\mathrm{kg}^{-1}\right)\end{array}$ & $\begin{array}{c}\text { Total } \\
\text { alkalinity } \\
\left(\mu \mathrm{mol} \mathrm{kg}^{-1}\right)\end{array}$ \\
\hline $\mathrm{LC}$ & $8.19 \pm 0.02^{\mathrm{a}}$ & $2025.4 \pm 85.8^{\mathrm{a}}$ & $1809.5 \pm 70.0^{\mathrm{a}}$ & $203.3 \pm 15.6^{\mathrm{a}}$ & $12.6^{\mathrm{a}}$ & $2319.3 \pm 104.1^{\mathrm{a}}$ \\
$\mathrm{HC}$ & $7.83 \pm 0.02^{\mathrm{b}}$ & $2208.9 \pm 92.6^{\mathrm{b}}$ & $2072.5 \pm 84.2^{\mathrm{b}}$ & $104.0 \pm 8.4^{\mathrm{b}}$ & $32.3^{\mathrm{b}}$ & $2336.9 \pm 102.8^{\mathrm{a}}$ \\
\hline
\end{tabular}


Table S2 Nucleotide sequences of primers used in the real-time quantitative PCR

\begin{tabular}{|c|c|c|c|}
\hline Gene & $\begin{array}{c}\text { Primer } \\
\text { name }\end{array}$ & Sequences $\left(5^{\prime}-3^{\prime}\right)$ & $\begin{array}{l}\text { Amplicon } \\
\text { size (bp) }\end{array}$ \\
\hline \multirow{2}{*}{ Histone H4 } & $\mathrm{H} 4-\mathrm{F}$ & AGGCAAAGCGTGGTGTTCTTA & \multirow{2}{*}{156} \\
\hline & $\mathrm{H} 4-\mathrm{R}$ & TCTGGGGAGCCTCAGTCAATA & \\
\hline \multirow{2}{*}{$\begin{array}{c}\text { Synthase of mitochondrial } \\
\text { ATP synthase }\end{array}$} & SM-F & AGGACAATACCAGCCCTACGAACCG & \multirow{2}{*}{147} \\
\hline & SM-R & ACCTTGGAGTGGACACCCTTGACAT & \\
\hline \multirow{2}{*}{ Nitrite reductase } & NR-F & ATTGGGTGATTTCGCTTGAGAG & \multirow{2}{*}{182} \\
\hline & NR-R & CACCTCACTCGTCCCTTGTTCT & \\
\hline \multirow{2}{*}{$\begin{array}{l}\text { Fucoxanthin chlorophyll } \\
\text { a/c protein, lhcf type }\end{array}$} & FC-F & CGGCTGGGACACCTTTGACG & \multirow{2}{*}{197} \\
\hline & FC-R & ATCTTGGAAACGACGGCAGTATC & \\
\hline \multirow{2}{*}{ Carbonic anhydrase } & $\mathrm{CA}-\mathrm{F}$ & TGGGAACTGAGGCTGGAACC & \multirow{2}{*}{162} \\
\hline & CA-R & AAGCACGGACACCACCACATT & \\
\hline \multirow{2}{*}{$\begin{array}{l}\text { NADH dehydrogenase } \\
\text { subunit } 2\end{array}$} & $\mathrm{NADH}-\mathrm{F}$ & TATTGGTTGCGGTGTTAGGTC & \multirow{2}{*}{155} \\
\hline & NADH-R & GAAATACTTAATACCCGCCTCA & \\
\hline \multirow{2}{*}{$\begin{array}{l}\text { Peroxisomal membrane } \\
\text { protein-related }\end{array}$} & PMP-F & ATCTTGGTGGTGTAATCGTCC & \multirow{2}{*}{205} \\
\hline & PMP-R & GTTCCTTTGGTTTCCTCCTG & \\
\hline \multirow{2}{*}{$\begin{array}{c}\text { Ribulose-1,5-bisphosphate } \\
\text { carboxylase/oxygenase } \\
\text { large subunit }\end{array}$} & Rbcl-F & TCAATACTTCGCTTTTATCGCAT & \multirow{2}{*}{176} \\
\hline & Rbcl-R & CAGTAGCAGGACCTTGGAACG & \\
\hline
\end{tabular}




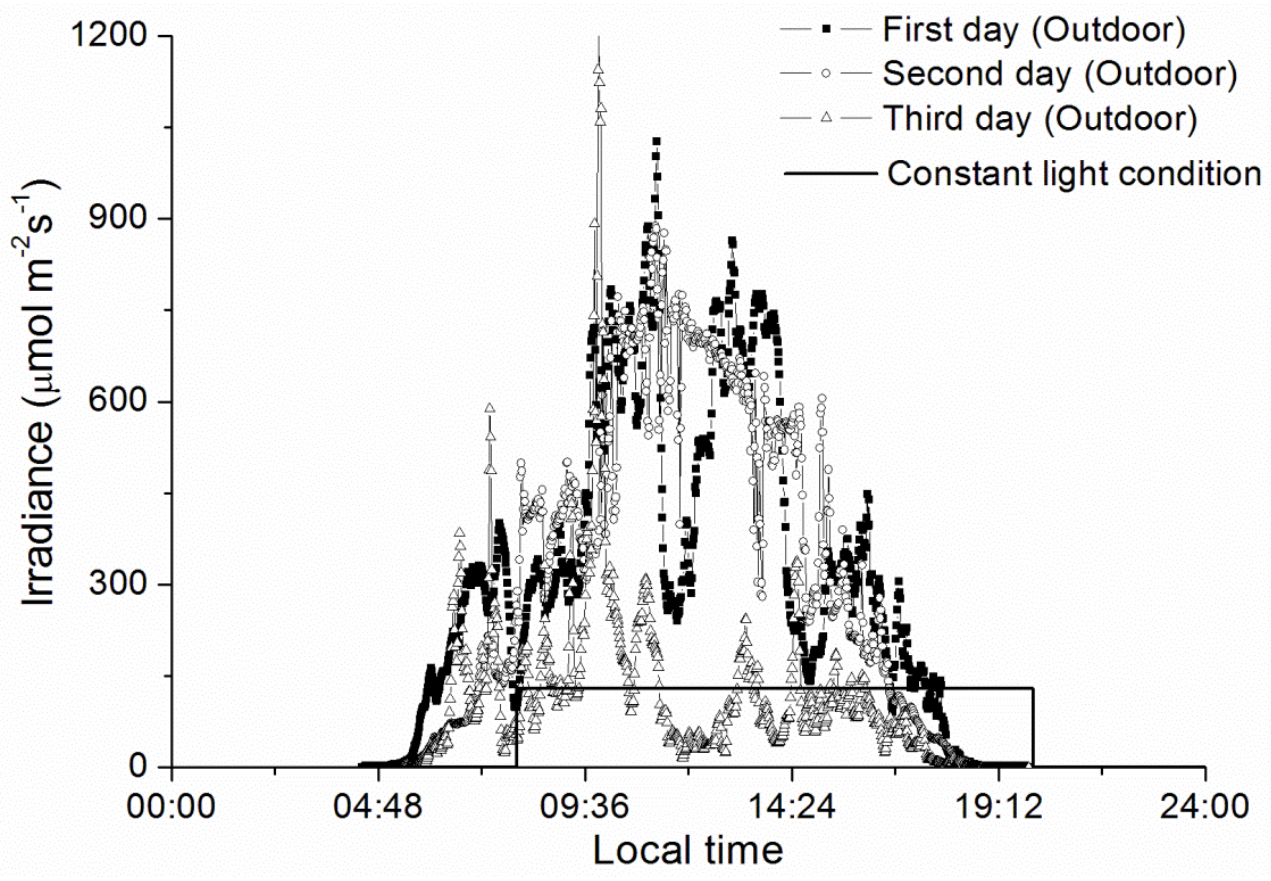

Fig. S1 Light conditions during the experiments. 


\section{Reference}

Dickson, A. G.: Standard potential of the reaction: $\mathrm{AgCl}(\mathrm{s})+{ }^{1} / 2 \mathrm{H}_{2}(\mathrm{~g})=\mathrm{Ag}(\mathrm{s})+$ $\mathrm{HCl}$ (aq), and the standard acidity constant of the ion $\mathrm{HSO}_{4}{ }^{-}$in synthetic seawater from 273.15 to 318.15 K. J. Chem. Thermodyn., 22, 113-127, 1990.

Lewis, E., and Wallace, D. W. R.: Program Developed for $\mathrm{CO}_{2}$ System Calculations, ORNL/CDIAC-105, Carbon Dioxide Information Analysis Center, Oak Ridge National Laboratory, US Department of Energy, 1998.

Roy, R. N., Roy, L. N., Vogel, K. M., Porter-Moore, C., Pearson, T., Good, C. E., Millero, F. J., and Campbell, D. M.: The dissociation constants of carbonic acid in seawater at salinities 5 to 45 and temperature 0 to $45^{\circ} \mathrm{C}$, Mar. Chem., 44, 249-267, 1993. 